\title{
ESPAÑOLES INSTRUIDOS POR LA CONSTITUCIÓN
}

PILAR GARCÍA TROBAT

Universitat de València 
SUMARIO

1. INTRODUCCIÓN. 2. CONSTITUCIÓN Y LIBERTAD DE IMPRENTA: 2.1. Libertad de imprenta e Inquisición. 2.2. Enseñanza de la Constitución. 3. DIRECCIÓN GENERAL DE ESTUDIOS. 4. PROYECTO DE PLAN DE INSTRUCCIÓN PÚBLICA: 4.1. Bases de la enseñanza pública. 4.2. Primera enseñanza. 4.3. Segunda enseñanza. 4.4. Tercera enseñanza. 4.5. De los fondos. 


\title{
ESPAÑOLES INSTRUIDOS POR LA CONSTITUCIÓN
}

POR

\author{
PILAR GARCÍA TROBAT \\ Universitat de València
}

\section{INTRODUCCIÓN}

En el siglo XVIII muchos ilustrados demandaron un arreglo de la instrucción pública. ${ }^{1}$ Se tenía la certeza de que sólo ella podía remover muchos de los obstáculos que impedían el progreso. ${ }^{2}$ El gobierno liberal, recogiendo este testigo, convirtió también la educación pública en una de sus mayores preocupaciones. ${ }^{3} \mathrm{~A}$ pesar de las circunstancias de guerra y en medio de los mayores apuros, los escritores clamaron por una reforma en la educación. El voto de la Nación española en sus primeras páginas hizo alusión a la ignorancia de la Nación como «origen de todos los males que sufrimos» y la consideró «el arma en que el tirano confía más para sojuzgar toda la Europa.» ${ }^{4}$ Se pidió la instrucción del pueblo. Mantenerlo ignoran-

${ }^{1}$ Mariano y José Luis PESET, La universidad española (Siglos XVIII y XIX). Despotismo ilustrado y revolución liberal, Madrid, Taurus, 1974.

2 «Con la instrucción todo se mejora y florece, sin ella todo decae y se arruina en un estado», Gaspar Melchor de JOVELLANOS, «Memoria sobre la educación pública», Obras publicadas e inéditas, colección hecha e ilustrada por Cándido Nocedales, Madrid, BAE, 1858, I, 230-267, p. 231.

3 Mariano PESET, «La enseñanza del derecho y la legislación sobre Universidades, durante el reinado de Fernando VII (1808-1833),» Anuario de Historia del Derecho Español, 38 (1968), 229375, p. 249; Pilar GARCÍA TROBAT, «Una aspiración liberal: la enseñanza para todos», Materiales para el estudio de la Constitución de 1812, Madrid, Tecnos, 1992, 303-311.

${ }^{4}$ El voto de la Nación española, núm. 1, miércoles 13 de diciembre de 1809, p. 10. 
te había sido una necesidad del gobierno despótico, ayudado por la Inquisición. Y se relacionó la instrucción con los principios de la revolución, «ni constituciones, ni leyes, ni reformas parciales son suficientes para sacarnos de la horrible decadencia.» Instrucción y Constitución debían ir de la mano. Era menester reformar la nación, en sus individuos, inspirándoles ideas liberales, amor a la Constitución y seguridad en sus derechos de hombres libres. La instrucción en los principios políticos les haría libres y significaría la mejor defensa de una nación frente a cualquier ataque. Para el Semanario patriótico sólo cuando hasta el más pobre trabajador entendiera de los asuntos políticos y los discutiera en medio de su familia, la nación sería libre y no habría nada que temer. ${ }^{5}$ No solo las fuentes de riqueza -agricultura, industria, comercio, navegación...- dependían de la instrucción pública, también, la consolidación del régimen liberal. Los rústicos permanecían en la ignorancia más absoluta, pero en las universidades los estudios no estaban en mejor situación. El Conciso lo resumía así:

Se han extraviado los estudios. Al mismo tiempo que los hombres ignoraban la naturaleza del terreno que los mantenían y el modo de hacerle más fructífero, se volvían locos estudiando una astrología tan arbitraria como inútil, y discutiendo puntos de teología que están fuera de los límites del entendimiento humano y que solo pueden servir de vana ostentación. Esta fatalidad se echa de ver particularmente en la ciencia de gobierno; esta ciencia que enseña el modo y los medios de hacer a los hombres buenos y felices en la sociedad, que influye sobre todos los hombres civilizados y es capaz de civilizar a todos los salvajes, debió ser cultivada con esmero desde el momento en que se reunió en sociedad el género humano. A pesar de esto ¿cuáles son los libros españoles que desempeñen dignamente tan importante objeto? ¿dónde está la cátedra destinada a la enseñanza de esta ciencia? Mas ay! Cómo ha de haber tal cátedra cuando todavía se conserva en nuestra Novísima Recopilación la ignominiosa y bárbara ley que prohíbe en todo el reino las cátedras y la enseñanza del derecho natural y de gentes? ${ }^{6}$

La Junta Central, al poco de partir Fernando VII hacia su cautiverio, encomendó su reforma a una comisión presidida por Jovellanos. ${ }^{7}$ Se redactaron las $B a-$

5 Semanario patriótico, núm. 26, jueves 20 de julio de 1809, pp. 189-190.

${ }^{6}$ El Conciso, núm. 5, sábado 5 de diciembre de 1812.

7 El 22 de mayo de 1809 la Junta Central decretó se consultase sobre las reformas necesarias en instrucción y educación pública, Gazeta del Gobierno, núm. 34, lunes 5 de junio de 1809, pp. 566-568; Miguel ARTOLA recoge muchas de las respuestas a esta consulta en el segundo volumen de Los orígenes de la España contemporánea, 2 vols., Madrid, Centro de Estudios Políticos y Constitucionales, 2000. Primera edición en Madrid, Instituto de Estudios Políticos, 1959; Algunas respuestas, coincidiendo con los proyectos educativos de los revolucionarios franceses, hablaron de la necesidad de una instrucción universal, uniforme, gratuita e incluso obligatoria, Narciso de GA- 
ses para la formación de un plan de Instrucción pública donde se expresarían algunos de los principios que informarán posteriormente esta materia. ${ }^{8}$ Pero la Junta desapareció y traspasó sus poderes al Consejo de Regencia el 31 de enero de 1810.

\section{CONSTITUCIÓN Y LIBERTAD DE IMPRENTA}

Instaladas las Cortes, en medio de la guerra se decretó a propuesta de Espiga y Gadea la formación de una comisión de educación pública que propusiera los medios y el plan conveniente para proporcionarla a todos los españoles. ${ }^{9}$ Sin tener efecto esta resolución, se sancionó la Constitución dedicándole todo un título, el IX, a la Instrucción pública. El discurso preliminar subrayaba su necesidad:

El estado no menos que de soldados que le defiendan, necesita de ciudadanos que ilustren a la Nación, y promuevan su felicidad con todo género de luces y conocimientos. Así que, uno de los primeros cuidados que deben ocupar a los representantes de un pueblo grande y generoso es la educación pública. Esta ha de ser general y uniforme, ya que generales y uniformes son la religión y las leyes de la monarquía española. ${ }^{10}$

El título IX fue considerado como el «coronamiento» de la Constitución. ${ }^{11}$ Tan importante era la instrucción del pueblo, decía el diputado Pelegrín, que mereció un título especial, porque sin Constitución no había patria, pero sin educación no se lograrían «los bienes que deben esperar de su observancia.» ${ }^{12}$ Se colocaba, entre los objetos más importantes que debía atender el gobierno, en primer lugar la educación pública. «La esclavitud de los pueblos, la miseria, los errores acreditados, las preocupaciones, los malos hábitos, las pasiones desenfrenadas, las malas leyes, las malas instituciones, los malos gobiernos, las guerras intestinas, o los contrastes de la opinión pública, y cuantas plagas afligen a la sociedad, todas, son consecuencia de la ignorancia de los hombres por defecto de un buen plan de

BRIEL, Prólogo a la edición española de Condorcet, Cinco memorias sobre la Instrucción pública, presentación, notas, bibliografía y cronología por Charles Coutel y Catherine Kintzler, Madrid, ediciones Morata, S.L., 2001, 11-46, p. 18.

8 Mariano PESET, «La enseñanza del derecho...,» p. 249.

9 Diario de sesiones, núm. 74, 9 de diciembre de 1810, p. 39. Sobre los resultados de esta proposición, véase Mariano PESET, «La enseñanza del derecho...,» p. 253, n. 37.

${ }^{10}$ Discurso preliminar leído en las Cortes al presentar la comisión de Constitución el proyecto de ella, Reimpreso en Madrid, Imprenta que fue de García, 1820, p. 113.

${ }^{11}$ Dictamen y proyecto de decreto sobre el arreglo de la enseñanza pública, presentados a las Cortes por su comisión de Instrucción pública y mandados imprimir de orden de las mismas, s.l., s.a., p. 4.

12 Diario de sesiones, núm. 653, 9 de septiembre de 1812, p. 3672. 
educación pública.» ${ }^{13}$ En un único capítulo, distribuido en seis artículos la Constitución fijaba las bases de la enseñanza liberal, garantizaba el estudio de la misma y consagraba la libertad de imprenta ${ }^{14}$ Los principios de enseñanza tardarán en concretarse en un plan de instrucción pública. No pasará lo mismo con la libertad de imprenta o la enseñanza de la Constitución.

\subsection{Libertad de imprenta e Inquisición}

La imprenta empezó a desenvolverse libremente en España durante la guerra de independencia, antes de que una ley lo autorizara. El despertar del pueblo contra el ejército de Napoleón vino acompañado de escritos que hablaban de «reformas de gobierno, planes de constitución, examen y reducción del poder y apenas se publicaría escrito alguno en España que no se dirigiese a estos objetos importantes.» ${ }^{15}$ Se escribía, se publicaba, se circulaba y se leía y se repetía en todas las provincias, «no obstante que la imprenta conservaba cuantas restricciones y trabas la habían encadenado en España.» ${ }^{16}$ Flórez Estrada, Jovellanos, Alcalá Galiano, Calvo de Rozas, Isidoro Morales, El Español, Semanario patriótico, El voto de la nación, El Conciso, Diario de Mallorca,... escribieron sobre su conveniencia. ${ }^{17}$ Fue

13 Abeja española, núm. 285, miércoles 23 de junio de 1813, pp. 181-182.

14 «Las Cortes de Cádiz tomaron conceptos e ideas presentes en el absolutismo ilustrado y los llevaron al plano legal,» Antonio VIÑAO, «La educación cívica o del ciudadano en la ilustración española: entre la tradición republicana y el liberalismo emergente,» Res publica. Revista de filosofía política 22 (2009), 279-300, p. 294.

15 «Reflexiones acerca de la Carta sobre el modo de establecer un Consejo de Regencia con arreglo a nuestra Constitución,» Semanario Patriótico, núm. 4, jueves 22 de septiembre de 1808, p. 62.

16 Agustín ARGÜELLES, Examen histórico de la reforma constitucional, 2 vols., Londres, Imprenta de Carlos Wood e hijo, 1835, I, p. 329.

17 Antonio ALCALÁ GALIANO, Máximas y principios de la legislación universal, Madrid, Imprenta de Vega y Compañía, 1813, pp. XIX-XX, en nota: «la confianza que me prestaba el carácter noble de los Españoles, su uniformidad de sentimientos y su moralidad, me obligó en el año 1809, deseoso de la ilustración de mis conciudadanos, fuese uno de los primeros promovedores de la ley de la imprenta;» Álvaro FLÓREZ ESTRADA, En defensa de las Cortes; con dos apéndices, uno sobre la libertad de imprenta y otro en defensa de los derechos de reunión y de asociación, Madrid, Ciencia Nueva, 1967, 141-151, cita en p. 145. El Voto de la nación española abrió su primer número, el miércoles, 10 de diciembre de 1809, con el titular: «La ilustración y la virtud hacen a las Naciones libres e independientes,» y consideraba la libertad de imprenta necesaria para la instrucción pública. JOVELLANOS se manifestó a favor de esta libertad pero consideraba conveniente que primero se aprobara la Constitución, «Memoria en que se rebaten las calumnias divulgadas contra los individuos de la Junta Central del Reino y se da razón de la conducta y opiniones del actor desde que recobró su libertad,» Obras publicadas e inéditas, colección hecha e ilustrada por Cándido Nocedales, Madrid, BAE, 1858, I, 503-573, p. 557. 
una de las primeras cuestiones que se trataron en las Cortes recién instaladas. El 10 de noviembre de 1810 se decretó la libertad política de imprenta. ${ }^{18}$ El 11 se dio orden a la Regencia para que mandase imprimir el decreto, publicarlo y circularlo. El día 15 se publicará en La Gazeta de la Regencia de España e Indias. ${ }^{19} \mathrm{La}$ Constitución consagró en su texto el decreto ya sancionado.

Como los ilustrados, los liberales la vincularon a la enseñanza. ${ }^{20}$ Uno de los principales motivos señalados por el legislador para decretarla fue considerarla el medio más importante para «ilustrar a la Nación en general.» ${ }^{21}$ Flórez Estrada ya había señalado:

¿cómo podrán los hombres recibir la educación conveniente en un país donde no les es permitido oír, ni decir, leer, ni escribir lo que se siente? ¿Y cómo podrán adquirir las buenas ideas en donde el gobierno proscribe todas las que no se acomodan a su interés mal entendido? La libertad de imprenta es el único medio de que podemos valernos para arrancar de una vez males tan inveterados y tan insoportables; es el único remedio con que se puede mejorar nuestra educación abandonada. ${ }^{22}$

El decreto de libertad de imprenta preparaba el camino a la reforma de la instrucción pública. ${ }^{23}$ Nada contribuía más directamente a la ilustración de las naciones y a su independencia que la libertad de imprenta, verdadero vehículo de las luces. De ahí que tuviera que formar parte de la ley fundamental y recogerse precisamente en el título dedicado a la Instrucción pública. ${ }^{24}$ El artículo 371 re-

${ }^{18}$ El Conciso adelantó la publicación del decreto en un número extraordinario, núm. 30, miércoles 7 de noviembre de 1810, pp. 193-196.

19 Gazeta de la Regencia de España e Indias, núm. 95, 15 de noviembre de 1810, pp. 908-910.

20 Se necesitaban hombres cultos para poder hacer frente al fanatismo y a la superstición, para llevar la luz de la razón, véase, Francisco, FERNÁNDEZ SEGADO, «La libertad de imprenta en las Cortes de Cádiz», Revista de estudios políticos (Nueva época) 124 (abril-junio, 2004), 29-54, p.

${ }^{21}$ Decreto IX de 10 de noviembre de 1810, Libertad política de la Imprenta, Colección de los decretos y órdenes que han expedido las Cortes generales y extraordinarias desde su instalación de 24 de septiembre de 1810 hasta igual fecha de 1811, Madrid, imprenta nacional, 1813, I, p. 14. El Censor general, núm. 3, martes 17 de noviembre de 1812, p. 10 publicaba el decreto pero sustituyó la exposición de motivos por esta otra más sugerente: «Cerciorada la junta de lo que el público ansía tener el decreto de las Cortes sobre la libertad de la imprenta, que muchos que pudieran escribir con utilidad de sus semejantes no lo hacen por no saber baxo qué reglas han de ejecutarlo y de que algunos que lo tienen quieren que se lo paguen a peso de oro, para que todo ciudadano pueda usar de él como le acomode, acordó su publicación.»

22 Álvaro FLÓREZ ESTRADA, En defensa de las Cortes; con dos apéndices..., p. 145.

23 «Fanal de la instrucción, sin cuya luz navegaríamos por un piélago de tinieblas», consideraba Conde de TORENO, Historia del levantamiento, guerra y revolución de España, Madrid, Imprenta de Don Tomás Jordán, 1835, IV, p. 386.

${ }^{24}$ Discurso preliminar leído en las Cortes..., pp. 114-115. 
conocía a todos los españoles «la libertad de escribir, imprimir y publicar sus ideas políticas sin necesidad de licencia, revisión o aprobación alguna anterior a la publicación, bajo las restricciones y responsabilidad que establezcan las leyes.»El artículo 131.24 dejaba además especialmente a las Cortes su protección. ${ }^{25}$

La discusión sobre la ley de imprenta dividió a los diputados «en dos partidos tan distantes entre sí por sus opiniones, intereses y miras como el norte del mediodía. Uno pequeño y obligado a disimular sus principios; el otro numeroso y sostenido por las preocupaciones de la masa del pueblo: ambos exagerados y extremosos.» ${ }^{26}$ El pequeño logró la victoria y se decretó la libertad que necesitaba para imponer sus reformas; pero esta victoria, aunque importante, no lo fue total. En los debates se sorteó una cuestión importante que por todos los medios trataron de evitar: la Inquisición. No tenían mayoría, ni el público estaba instruido sobre la cuestión. Como confesará Argüelles «entrar de improviso en una cuestión tan escabrosa, sin haberla preparado ni ilustrado todavía, dando tiempo al examen de la materia por medio de la imprenta libre, era tan incongruente como peligroso. ${ }^{27} \mathrm{La}$ suerte de la libertad de imprenta y de la instrucción pública dependían de su abolición. El Semanario patriótico fue el encargado de ir disponiendo al público contra el tribunal del Santo Oficio. ${ }^{28}$ Si bien no faltó quien, atento ante tales críticas, llamó la atención de lo que se pretendía. ${ }^{29}$ La mayoría de los españoles estaba a favor de su mantenimiento no solo porque veía en ella el garante de la fe de sus padres, sino también porque Napoleón la había suprimido. En momentos en los que se estaba luchando contra quien consideraban el Anticristo, ésta era razón de gran peso. Na-

${ }^{25}$ En la discusión en torno a este artículo sorprendió al marqués de Villafranca que se le diera preferencia sobre las demás leyes. Muñoz Torrero, aclaró que no velaban las Cortes por el cumplimiento del decreto sino por la misma libertad. Como este derecho de los españoles tenía por objeto servir de freno al gobierno, las Cortes debían protegerlo para que nunca gobierno pudiera destruirlo, Diario de sesiones, núm. 367, 4 de octubre de 1811, pp. 1986-1987.

${ }^{26}$ El Español, mayo y junio de 1814, p. 300

27 Agustín ARGÜELLES, Examen histórico de la reforma..., p. 331.

${ }^{28}$ Otros le siguieron, Natael JOMTOB (Antonio Puigblanch), La Inquisición sin máscara o disertación en que se prueban hasta la evidencia los vicios de este tribunal y la necesidad de que se suprima, Cádiz, Imprenta de Don José Niel, 1811; Ingenuo TOSTADO (José Antonio Llorente), Incompatibilidad española con el establecimiento de la Inquisición, Cádiz, Vicente Lerma, 1811. La prensa apologista censuró aquellas obras, véase, El Censor general, núm. 18, 1811, pp. 249-264. Otras formas de literatura se pusieron a favor de la causa liberal y en contra de la inquisición, véase, Jesús MARTÍNEZ BARO, «Las hogueras se extingan”: La Inquisición en la poesía de la prensa gaditana entre 1811 y 1813», Cuadernos de Ilustración y Romanticismo, 13 (2005), 109-139.

29 Apología de la Inquisición. Respuesta a las reflexiones que hacen contra ella el Semanario Patriótico número 61 y el Periódico intitulado El Español número 13 y breve aviso a los señores Arzobispos, Obispos y Diputados en Cortes, Cádiz, Oficina de Don Nicolás Gómez de Requena, 1811. 
poleón «lo aborrece extraordinariamente» y no era creíble «que lo hiciera para nuestra felicidad, un hombre que ha hecho a tantos infelices.» ${ }^{30}$ La prensa más reacia advierte que a los liberales les sobraba la Inquisición porque «reconocen por sus maestros a Montesquieu, Rousseau, Espinosa, Bayle, Puffendorf, Heinecio... y otros tales escritores del derecho natural y público; las luces que estos difunden como que son verdaderas tinieblas, son incompatibles con el Evangelio, único reglante de la razón ofuscada por las tinieblas de la ignorancia.» ${ }^{31}$

Al promulgarse la Constitución, desde la prensa se insistió mucho en iniciar los trabajos de reforma de los estudios, ${ }^{32}$ las universidades pedían a las Cortes un plan por el que regirse, se abrieron cátedras y escuelas sin que el plan llegara... ${ }^{33}$ Pero los liberales aplazaron su elaboración. No podían llevarlo adelante sin antes resolver la cuestión de la Inquisición. Desde su tribuna, en la prensa, se insistió machaconamente en su incompatibilidad con la Constitución. La división entre absolutistas y liberales, en las Cortes y fuera de ellas, se manifestó entonces muy profunda. Por fin se debatió en las Cortes. En la discusión del proyecto de decreto sobre el tribunal, ${ }^{34}$ Ruiz de Padrón, uno de los más destacados defensores de su abolición, ${ }^{35}$ habló en contra de «este sombrío y cauteloso tribunal,» y de

30 Apología de la Inquisición..., p. 8

31 El Censor general, núm. 6, martes 14 de enero de 1812.

32 Un plan de instrucción pública que «todo lo abrace, todo lo enlace, todo lo calcule y todo lo ponga en su lugar, es sin duda la empresa más grande, más sublime, más vasta y de más trascendencia a la prosperidad pública, que puede y ha podido concebir el espíritu humano,» Abeja española, núm. 286, jueves 24 de junio de 1813, pp. 191-192; «La educación pública es ramo tan interesante a un Estado, que por lo común decide sobre su prosperidad o su abatimiento,» El Duende de los cafees, núm. 38, martes 7 de septiembre de 1813, p. 157.

33 Se pide la reforma en los estudios de medicina con una mayor coordinación entre las facultades de medicina, farmacia y cirugía, El Conciso, núm. 13, viernes 13 de marzo de 1812. Se aceptan solicitudes para abrir escuelas según planes que presentan algunos particulares en tanto se aprueba el general para la monarquía, véase por ejemplo el de Campeche en Yucatán, Diario de sesiones, núm. 829, 21 de marzo de 1813, p. 5083; se establecen cátedras de economía civil y escuelas de agricultura según Decreto CCLXI de 8 de junio de 1813, sobre el establecimiento de cátedras de agricultura y de sociedades económicas. «Se establecerán en todas las universidades de la monarquía los más pronto que sea posible, cátedras de economía civil; en todos los pueblos principales o por lo menos en todas las capitales escuelas prácticas de agricultura; las Cortes oyendo por medio del gobierno a la Dirección general de estudios, arreglarán el plan que deba observarse en unos y otros establecimientos.»

34 Se publicó el debate, en el Diario de sesiones, y además en un tomo suelto, Discusión del proyecto de decreto sobre el tribunal de la inquisición, Cádiz, Imprenta nacional, 1813.

35 José RUIZ de PADRÓN publicó su Dictamen del doctor D. Antonio José Ruiz de Padrón, ministro calificado del Santo Oficio, abad de Villamartín de Valdeorres y diputado en Cortes por las Islas Canarias que se leyó en la sesión pública de 18 de enero sobre el tribunal de la inquisición, Cádiz, Imprenta Tormentaria, 1813. 
cómo «la España estará condenada a una perpetua ignorancia» mientras subsistiera. No faltó quien le respondiera.

No llegue a ilustrarse el pueblo español si la ilustración ha de adquirirse por medio del libre curso y lectura de libros y obras, en que a la par de algunas máximas útiles, sea en la física, sea en la metafísica, sea en la moral, o sea aún en la estadística y diplomacia, se siembra y derrama el mortal veneno de la invectiva, del sarcasmo, de la sátira burlesca con que se denigran y obscurecen las verdades de más importancia, tanto más perjudicial quanto encubierto y confundido con aquellas mismas máximas, que alucinando y encantando en razón de la utilidad que presentan, ofuscan la razón, de modo que no lo descubra ni perciba; y así se vaya extraviando hasta el término de imbuirse de principios de impiedad e irreligión. ${ }^{36}$

Ruiz de Padrón recordaba aquellos años en que «para que un español pudiera leer a un Mably, a Condillac, Filangieri... y lo que es más asombroso, para leer a Pascal, Duguet, Arnaldo, Racini, Nicole y a otros sabios y piadosos autores proscritos por este fanático y estúpido tribunal, era necesario ocultarse en una buhardilla.» ${ }^{37}$ Los absolutistas temían que si a pesar de la Inquisición, «tiempo hacía que el jansenismo andaba remolcando en España,» qué no pasaría sin ella. El abate Hervás aseguraba que en Italia se habían embarcado «caxones de libros jansenistas para un catedrático de Salamanca... venían en aquellos sepulcros los amigos de aquellos congregantes de Cádiz, los Augustinos, los Tamburinis, los Quesneles, los piadosísimos Sacis con toda la otra chusma... ${ }^{38}$ La Inquisición quedó abolida el 22 de febrero de 1813. Tras la reacción absolutista, acordándose de los discursos pronunciados en contra de la Inquisición se escribiría, «qué plan de estudios saldría de tales maestros. ${ }^{39}$

\subsection{Enseñanza de la Constitución}

El artículo 368 disponía que debía explicarse la Constitución política de la Monarquía en todas las universidades y establecimientos literarios, donde se

36 Pensamientos ocurridos a un observador sobre el voto que el señor Ruiz de Padrón, diputado en Cortes dio con el objeto de promover la abolición del Tribunal de la Inquisición, publícalos el editor del Sensato, Santiago, Oficina de D. Juana María de Pazos, 1813, p. 57; Antídoto verdadero contra la doctrina de tres proposiciones, que se leen en un dictamen dado por el Dr. D. Antonio José Ruiz de Padrón, ministro calificado del Santo Oficio, Abad de Villamartín, sobre el tribunal de la inquisición. Recetado para desengañar al público. Por el R. Jayme CABRUJA, presbítero de Reus, Reus, oficina de Rubió, 1813.

37 Discusión del proyecto de decreto sobre el tribunal de la Inquisición..., p. 366.

38 El Procurador general del rey y de la nación, núm. 110, domingo 18 de septiembre de 1814, p. 896.

39 El Procurador general del rey y de la nación, núm. 110, domingo 18 de septiembre de 1814, p. 893. 
enseñasen las ciencias eclesiásticas y políticas. ${ }^{40}$ Se miraba la enseñanza de la juventud como «el sostén y apoyo de las nuevas instituciones.» ${ }^{41}$ Algunos particulares se encargaron de su explicación sin esperar a que el plan de instrucción pública se aprobara. Se establecieron en pueblos y ciudades clases de Constitución para los más pequeños. Utilizaron el mismo texto de la Constitución como cartilla de lectura y la recitaban de memoria igual que el catecismo religioso.

También en las universidades se instalaron cátedras de Constitución. En la universidad de Salamanca la explicó el doctor Tiburcio Gutiérrez en la cátedra de Recopilación. Mientras se «determinasen el método a observar y el tiempo que debía dedicar a la explicación de la Constitución, si un período concreto del curso o una parte de la clase diaria,» se atuvo a la misma forma que se había utilizado para integrar el derecho patrio en el Corpus, es decir concordando los artículos de la Constitución con las leyes recopiladas. ${ }^{42}$ En la universidad de Valencia, Nicolás María Garelly, catedrático también de Recopilación, ${ }^{43}$ se encargó de su explicación. Él mismo lo solicitó a las Cortes. Expuso en su petición que hacía diez años que trataba de inculcar en sus discípulos las «las máximas que aprendí en la obscuridad»y, sancionadas, creía necesario explicarlas para arraigar su planta. ${ }^{44}$

Los Estudios de San Isidro instalaron su cátedra de Constitución y publicaron el discurso de su apertura, al igual que Valencia. Se quería ilusionar al público con sus postulados; su conocimiento no debía reservado para los literatos, como

40 Sobre la enseñanza de la Constitución, véase, Pilar GARCÍA TROBAT, Constitución de $1812 y$ educación política, Madrid, Congreso de los diputados, 2010.

${ }^{41}$ Dictamen y proyecto de decreto sobre el arreglo de la enseñanza pública, presentados a las Cortes por su comisión de Instrucción pública..., p. 4.

${ }^{42}$ Véase $\mathrm{M}^{\mathrm{a}} \mathrm{Paz}$ ALONSO, «La Universidad de Salamanca ante la Constitución de Cádiz: actitudes políticas y académicas», Aulas y Saberes, 2 vols., Universitat de València, 2003, I, también su trabajo, «Del «amor» a las leyes patrias y su «verdadera inteligencia»: a propósito del trato con el Derecho regio en la Universidad de Salamanca durante los siglos modernos», Anuario de historia del derecho español, 67, 1 (1997), 529-549.

43 Sobre N. M ${ }^{a}$ Garelly, Mariano PESET, «Análisis y concordancias del proyecto de código civil de 1821», Anuario de derecho civil, 18 (1975), 29-100; «El catedrático valenciano Nicolás María Garelli se defiende ante la inquisición», Homenaje a José Antonio Maravall, 3 vols., Madrid, 1986, III, pp. 207-220; Pilar GARCÍA TROBAT, «Nicolás Mª Garelly y la Novísima recopilación, Aulas y Saberes», Universitat de Valencia, 2 vols., I, 445-462.

44 «Exposición de Garelly para que se le permita explicar la Constitución en la universidad de Valencia», firmada en Valencia, 21 de octubre de 1813, Archivo del congreso de los diputados, legajo 18, núm. 74. Instalación de la cátedra de Constitución en la ciudad de Valencia a cargo del pavorde Don Nicolás Gareli: hizola por orden de S.M. las Cortes y de S.A. la regencia del Reyno. El gefe superior político de esta provincia Don Mateo Valdemoro el día 14 de enero de este año, Valencia, 1814, publicada en Mariano PESET y Pilar GARCÍA TROBAT, «La Constitución de 1812 o cómo educar a un pueblo,» La enseñanza de las ideas constitucionales en España e Iberoamérica, Valencia, Ene, 2001, pp. 23-62. 
decía el director de San Isidro. ${ }^{45}$ A todos importaba y por todos debía ser conocida: «no hay español, por iliterato y rudo que sea, a quien no debamos instruir con paciencia en sus derechos y en sus obligaciones, que es en suma lo que la Constitución nos enseña.» Cualquier ciudadano debía conocer sus derechos y sus obligaciones. El concurso de todo tipo de público resultaba conveniente. La cátedra la regentaría Miguel García de la Madrid. ${ }^{46}$

La Academia de Derecho Español Público y Privado de México fue el primer establecimiento científico que enseñó la Constitución en Ultramar. Con ocasión del ejercicio público del trimestre, con arreglo a sus estatutos, se nombró a su secretario el licenciado Benito José Guerra, para que formase un discurso, al que replicarían, por medio de las correspondientes arengas, los licenciados Francisco de Azcárate y Juan Gómez Navarrete. ${ }^{47}$ De otras universidades solo consta su intención de obedecerlo. ${ }^{48}$

Junto a estas clases o cátedras académicas, aparecieron otras que jugaron un papel muy importante: las publicaciones periódicas y los folletos. Se consideró a los escritores «elegidos por la providencia, apóstoles políticos de la Nación,» «sus maestros, sus directores, sus consejeros.» ${ }^{49}$ Las canciones, ${ }^{50}$ los poemas, las piezas

${ }^{45}$ Relación de la solemne apertura de la cátedra de Constitución politica de la monarquía española por los estudios de San Isidro de Madrid, en el día 25 de febrero de 1814. Publicada por acuerdo de los mismos estudios, Madrid, 1814, pp. 12-13. Publicada en Mariano PESET y Pilar GARCÍA TROBAT, «La Constitución de 1812 o cómo educar...»

46 En la Miscelánea de comercio, artes y literatura, núms. 67 y 68, lunes 3 y miércoles 5 de abril de 1820, p. 4; en ambos números, se recoge un discurso de un discípulo de esta cátedra.

47 Solemne acción de gracias que la academia de Derecho español, público y privado de la capital de México da al Supremo Congreso de las Cortes Generales y Extraordinarias por haber dictado la Constitución política de la Monarquía española, celebrada el día 15 de marzo de 1813, en el aula mayor del colegio más antiguo de San Pedro, San Pablo y San Ildefonso, México, Imprenta de Doña María Fernández de Jáuregui, 1814.

48 En Diario de sesiones de las Cortes generales y extraordinarias, 23 de octubre de 1812, núm. 685 , p. 3869, encontramos la representación de la universidad de Granada y en 27 de agosto de 1813, número 955, la de Valladolid. La universidad de Cervera, primero a través de su cancelario y rector (Dou) y después por todo el claustro de profesores se ofrecen, «como maestros públicos, difundir luces para su inteligencia, aprobación y observancia.» Pero piensan que deben esperar a que se afiance el sosiego «para poder inculcar y grabar desde la cátedra en el corazón de la juventud, la más profunda veneración, obediencia y constante adhesión a los principios y leyes consagradas en este inmortal código», Diario de sesiones, núm. 746, 15 de enero de 1813, p. 4569 y núm. 779, 23 de febrero de 1813, p. 4741.

49 El fiscal patriótico de España, núm. 15, lunes 29 de enero de 1813, p. 120.

50 No solo los constitucionalistas se dedicaron a difundir su mensaje a través de obras populares, los absolutistas utilizaron las mismas armas para contrarrestar la propaganda liberal. «En Madrid, en la puerta del sol, el pueblo amante de la Constitución que ha jurado y altamente ofendi- 
de teatro... se pusieron al servicio de la revolución. La constitución se predicó en los púlpitos. ${ }^{51} \mathrm{Y}$ se encargó a Diputaciones y ayuntamientos vigilar y fomentar la instrucción del pueblo en los principios liberales.

Si los pueblos no conocen las instituciones no pueden amarlas... los jefes políticos en sus observaciones sobre este punto deberán distinguir de los efectos constantes del convencimiento las ráfagas pasajeras del entusiasmo. Se manda, por ejemplo, publicar la Constitución, y que se hagan fiestas con tan justo y plausible motivo. Se publica en efecto la Constitución; se hacen las fiestas y las gentes andan como locas gritando por las calles: viva la Constitución ¿Y deberá aquietarse por eso el jefe político y no cuidará de instruir a los pueblos en lo que tanto les interesa y a lo que tanto aprecio y amor manifiestan? ${ }^{52}$

\section{DIRECCIÓN GENERAL DE ESTUDIOS}

El artículo 369 de la Constitución establecía que hubiese «una dirección general de estudios, compuesta de personas de conocida instrucción, a cuyo cargo estará, bajo la autoridad del Gobierno, la inspección de la enseñanza pública.» El discurso preliminar explicaba que para que el carácter de los estudios fuera nacional, «para que el espíritu público pueda dirigirse al grande objeto de formar verdaderos españoles, hombres de bien y amantes de su patria,» era preciso que no quedase «confiada la dirección general de la enseñanza pública a manos mercenarias.» Se necesitaba «formar una inspección suprema de instrucción pública,

do al ver este precioso código vulnerado en una canción subversiva y sediciosa que vendían los ciegos en contraposición de otra titulada Marica constitucional, rompió todos los ejemplares que llevaban los ciegos y estos echaron a correr por no ser víctimas del furor popular. Se asegura que a cada ciego le han dado gratis los ejemplares de la canción y además tres duros, para que la publicasen a gritos a fin de pervertir y corromper la opinión del pueblo... Se dice que El Procurador es el autor de esta canción sediciosa.» Redactor general, núm. 85, viernes 25 de marzo de 1814.

51 El Procurador general del rey y de la nación, núm. 110, domingo 18 de septiembre de 1814, pp. 891-897. «Quando vi que se levantaban cátedras hasta en las mismas iglesia para explicar y sutilizar el derecho civil constitucional, o novísima y fundamental recopilación de los derechos imprescriptibles e inalienables, y vi también a unos majaderos sentados en su cátedra de pestilencia con la seriedad de un doctor rabino explicando este Pentateuco lleno de sublimes misterios y enigmas profundos; ea, vamos, dixe, seguros son los toros; los estudios de la monarquía española van a recibir el último grado de ellos que están formando con sumo cuidado y aplicación aquellos padrastros de la patria salga a luz; ¿qué luces no difundirán por todos los rincones más escondidos de la ennochecida patria?»

52 Periódico ministerial intitulado Correo político y económico de las provincias de la Península, núm. 1, 1814, pp. 28-29. 
que con el nombre de dirección general de estudios, pueda promover el cultivo de las ciencias.» La dirección tenía que centralizar los estudios, bajo la protección del Gobierno y la vigilancia de las Cortes. Meses después de aprobada la Constitución el diputado Pelegrín proponía:

Que la Comisión de Constitución, con la brevedad que le permitan sus muchas atenciones, diga a V.M. si estamos ya en el caso de establecer la dirección general de estudios, con arreglo al artículo 369 de la Constitución y en su defecto que se nombre una comisión de dentro o fuera del Congreso que proponga los medios y reglamentos necesarios para llevar a efecto los tres artículos primeros del título IX de dicho código. ${ }^{53}$

Un año más tarde, la falta de cumplimiento de este artículo suscitó críticas y murmuraciones. La Abeja española, con su característico tono irónico, publicaba: «hay quien piensa que el motivo de no promoverse este asunto interesante nace de las intriguillas y cálculo (para lo futuro) de algunos Señores Caporales, que han llegado a decidir formalmente que fuera de ellos no conocen en la Nación personas capaces de desempeñar tan arduo y delicado encargo, y que siendo ésta una de las cosas no de la mayor urgencia, puede dexarse dormir hasta que sea tiempo hábil de...» ${ }^{54}$ Llamaba la atención este descuido u omisión. Y como decía la misma publicación no se podía poner de excusa que otros «negocios de mayor interés han absorbido el tiempo» pues solo tenían que nombrar los miembros que compusieran esta dirección general.

Pero en lugar de formarse una dirección general, la Regencia nombró una comisión para elaborar un plan general de instrucción publica. Estaba integrada por Quintana (secretario de la interpretación de lenguas), Navas (canónigo de San Isidro), Vargas (académico de la Historia), Tapia (encargado de la Gaceta del Gobierno) Clemencín y Cuadra (oficiales de la Gobernación de la Península y Ultramar). ${ }^{55} \mathrm{La}$ Abeja española de nuevo manifestó su extrañeza. En cuatro números consecutivos $^{56}$ hacía referencia a la dificultad de llevar a cabo un plan general de instrucción pública y consideraba que «seis literatos (de buena opinión sin duda, por su saber) no pueden encargarse de empresa tan superior a sus fuerzas y

53 Diario de sesiones, núm. 653, 9 de septiembre de 1812, p. 3672.

54 Abeja española, núm. 251, jueves, 20 de mayo de 1813, pp. 160 y ss.

55 Redactor general, núm. 735, sábado 19 de junio de 1813, p. 2976. También en Gazeta de Madrid baxo el gobierno de la Regencia de las Españas, núm. 23, martes 3 de agosto de 1813, p. 252.

56 Abeja española, núms. 285-288, miércoles-sábado, 23-26 de junio de 1813, pp. 181-186, 189-193, 197-201, 205-212. 
tan incompatible en la mayor parte con sus conocimientos.» ${ }^{57}$ Si se suponía que los sabios más distinguidos de la nación habían de ayudarles con sus luces « ¿por qué no dispensarles desde luego el honor de tenerlos presente para que desde un principio y en calidad de socios (y no de ayudantes, habiendo de tener que hacerlo todo, o la mayor y más difícil parte) empezasen sus tareas? ¿Se quiere por ventura que trabajen y otros se lleven la gloria?» No se entendía por qué en lugar de nombrar esta comisión no se había ejecutado el artículo 369 y formado una dirección general de estudios integrada por expertos en todas las ciencias para encargarse del plan.

¿Era acaso la dificultad saber el cómo había de procederse para la elección de los individuos, y el modo de organizar el cuerpo? Un anuncio en la gazeta del gobierno, en el que se exortase a los españoles (se entiende que no solo a los que estamos en Cádiz) a presentar el que quisiese en el término que se señalase, una memoria sobre el modo de elegir y organizar la sociedad literaria indicada, nos hubiera sacado del apuro completamente, siendo ésta la senda única, que a nuestro corto entender debió seguirse para conciliarlo todo. ${ }^{58}$

En septiembre de 1813 la comisión de Constitución presentaba a las Cortes un Dictamen y proyecto de decreto para la formación de la Dirección general de estudios. ${ }^{59}$ Excusaba su tardanza. Habían cambiado las circunstancias y era hora ya de encargarse del arreglo de la enseñanza. Pero no llegó a discutirse.

Mientras, las Cortes nombraron una comisión de Instrucción pública entre los diputados. Designaron a Eugenio de la Peña, José Miguel Gordoa, Andrés Navarro, José Joaquín Olmedo y Francisco Martínez de la Rosa. ${ }^{60}$ La urgencia de un nuevo plan de estudios llevó a que se pidiese comenzar por el establecimiento de escuelas de primeras letras ${ }^{61}$ o a que el diputado García Page presen-

57 Abeja española, núm. 287, 25 de junio de 1813, p. 199.

58 Abeja española, núm. 288, 26 de junio de 1813, pp. 209 y 210.

59 Diario de sesiones, núm. 968, 9 de septiembre de 1813, p. 6174.

60 Diario de sesiones, núm. 1, 1 de octubre de 1813, p. 10; posteriormente se añadieron García Page y Clemencín, Diario de sesiones, núm. 11, 10 de octubre de 1813, p. 103; Sánchez Diario de sesiones, núm. 30, 29 de octubre de 1813, p. 173; y Feliú y Mintegui, Diario de sesiones, núm. 34, 2 de noviembre de 1813 , p. 187.

${ }^{61}$ Diario de sesiones, núm. 25, 24 de octubre de 1813, p. 15. García Zamora propuso, teniendo en cuenta que los trabajos de la comisión de instrucción pública podían dilatarse, se nombrase una comisión especial o la misma de instrucción señalando un plazo para presentar un plan para establecer escuelas de primeras letras en todas las parroquias españolas, una por cada 300 vecinos, en ciudades y villas y por cada 50 en el campo. También proponía los medios económicos para poder ejecutar este plan. 
tara nuevas proposiciones para cubrir su falta. ${ }^{62}$ Pero esta vez la comisión de instrucción pública se dio prisa. Tomando como modelo el plan presentado a las Cortes por la junta comisionada por la Regencia, ${ }^{63}$ el 19 de febrero de 1814 anunció que había concluido su trabajo y que lo presentaría en la próxima legislatura. ${ }^{64}$ Efectivamente en la siguiente legislatura, con una renovada comisión de instrucción pública, ${ }^{65}$ Martínez de la Rosa leyó el dictamen y la minuta del

${ }^{62}$ Entre sus propuestas que se admitieron a discusión y se pasaron a la comisión de instrucción pública estaba que rigiera el plan Caballero en las universidades, en tanto se aprobaba el plan, y que se mandase formar un catecismo nacional elemental de doctrina cristiana, a imitación del que escribió el célebre Fenelón, encargando su formación a personas sabias que asociadas con seis obispos inspirasen confianza a los españoles. En el Proyecto de 1814 se recogerán dos de estas propuestas en los artículos 117 y 118: las universidades seguirán en ejercicio hasta la erección de los prescritos en este arreglo y en los colegios y seminarios conciliares el método será el más análogo posible al establecido en este plan general. No se admitió la que pretendía que se establecieran en las capitales unas juntas con el nombre de conservadoras de la moral pública. Diario de sesiones, núm. 10, 9 de octubre de 1813, p. 101 y núm. 12, 11 de octubre de 1813, pp. 107-108. A las proposiciones leídas por el secretario siguió un discurso: «Page tomó la palabra para hacer ver el deplorable estado en que se ve con mengua de la nación y del siglo XIX la ilustración española. Que para que se diese obediencia a la Constitución era preciso fijar la vista en los preciosos cimientos que habían se sostenerle; sin costumbres políticas nada hay, añadió, y éstas se hace necesario formarlas baxo un plan animado y uniforme. Como la religión es la única que ha sancionado la Constitución, las Cortes debían prestar atención a la formación de un catecismo para todas las naciones del dominio español, encargando su formación a cinco prelados eclesiásticos de notoria suficiencia y acreditadas ideas de amor a la Constitución, elegidos y nombrados por el congreso mismo ¿qué aspecto presenta el método de estudios en nuestras escuelas y universidades? Aun miramos con harto dolor generalizada la xerga escolástica o peripatismo; todavía se enseña por esta viciosa ruina en nuestro siglo. Ni se crea que nos ofreció más lisonjeras esperanzas el plan de estudios dado a las universidades en el reinado de Carlos IV por su ministro Caballero, más interesado en mirar por los derechos despóticos del trono que por los preciosos e imprescriptibles del pueblo. V.M. señor no puede ni debe desentenderse de estas observaciones que nacen de mi buen deseo y de la triste experiencia que mi carrera me ha producido. Quisiera a ejemplo de la Roma republicana se formase en las capitales y cabezas de partido unas juntas censorias, que al paso que celasen sobre la observancia de las sabias instituciones, lo hicieran de la moral pública y de las costumbres. No busco en ellas las pesquisas ni diligencias inquisitoriales sino las dulces y paternales máximas de que sirvan a la corrección de los extraviados,» Diario de Palma de Mallorca, núm. 105, martes 21 de diciembre de 1813, pp. 425-427.

63 Manuel José QUINTANA, «Informe de la Junta creada por la Regencia para proponer los medios de proceder al arreglo de los diversos ramos de instrucción pública,» Obras completas, Madrid, Imprenta y estereotipia de M. Rivadeneira, 1852, pp. 175-191; su presentación en las Cortes en Diario de sesiones, núm. 30, 29 de octubre de 1813, p. 173.

${ }^{64}$ Diario de sesiones, núm. 106, 19 de febrero de 1814, p. 495.

65 Estaba formada por el Obispo de Pamplona, Gabriel Ugarte y Alegría, José Domingo Mintegui, Francisco Martínez de la Rosa, Ignacio Ramón de Roda, Francisco Javier Caro, Joaquín Palacín, Salvador Sanmartín, Pedro Díez García, Diario de sesiones, núm. 1, 1 de marzo de 1814, p. 8. 
decreto y a propuesta del diputado Vargas, que aseguró que en Europa no había un plan como el que se presentaba, ${ }^{66}$ se autorizó su impresión. Estaba previsto que a los ocho días de repartirlo se empezara a discutir. ${ }^{67}$ Pero no dio tiempo.

El Dictamen y proyecto de decreto sobre el arreglo de la enseñanza pública, presentados a las Cortes por su comisión de Instrucción pública presentado el 17 de abril de 1814 volvió a regular la dirección general, ahora de forma más profusa y con algunas variantes respecto de la planta de 1813 . El Dictamen que precedía al Proyecto explicaba su significado. Hasta entonces, en España, cada establecimiento estaba sujeto a autoridades diferentes que dependían todas de la arbitrariedad un ministro; no había «ningún sistema acabado de educación nacional, ninguna reforma radical y duradera, ninguna armonía entre los diferentes ramos de enseñanza; en una palabra, ni método, ni concierto ni plan. ${ }^{68}$ La Dirección general estaba llamada a regular y dirigir las enseñanzas procurando la uniformidad. El Proyecto fijaba las bases generales de la enseñanza; la dirección, sobre ellas, conociendo los reglamentos de los establecimientos existentes y oyendo a los profesores más distinguidos, formaría los reglamentos particulares de estas escuelas. Estos reglamentos, se pasarían por medio del gobierno a la aprobación de las Cortes en conformidad con el artículo 370. Bajo la autoridad del gobierno, la independencia de sus miembros estaba garantizada ya que su cargo era incompatible con cualquier otro y no podían ser removidos sin justa causa. Para los territorios de Ultramar la comisión proponía el establecimiento de dos Subdirecciones de estudios, en México y Lima. Y para auxiliar a la Dirección general se formaba una Academia nacional como «gran foco de luz que contribuya eficazmente a la ilustración general de la nación.» Ramón Salas desconfiaba de la dirección general, que en Francia se llamaba universidad o academia y que estaba desacreditada ante la opinión pública porque por medio de ella los gobernantes se habían hecho dueños de la instrucción pública y la dirigían según convenía a sus intereses.

Competencia de la dirección general era el nombramiento de un cuerpo de examinadores para las oposiciones de catedráticos; oposiciones que debían realizarse todas ellas en Madrid. En Ultramar los examinadores se nombraban por las subdirecciones de México y Lima. Entre los motivos, que para centralizar los exámenes se esgrimen, estaban el asegurar una mayor concurrencia de aspirantes y con ella una oportunidad y facilidad mayor de hacer buenas elecciones; destruir

${ }^{66}$ Abeja madrileña, núm. 87, lunes 18 de abril de 1814, p. 350.

${ }^{67}$ Diario de sesiones, núm. 57, 17 de abril de 1814, p. 264.

${ }^{68}$ Dictamen y proyecto de decreto sobre el arreglo de la enseñanza pública, presentados a las Cortes por su comisión de Instrucción pública..., p. 18. 
el espíritu de cuerpo y de provincia; procurar la uniformidad en los estudios; conocer talentos y conocimientos de los opositores, a fin de emplearlos en destinos y comisiones diferentes en que sirvan al Estado. ${ }^{69}$

También la dirección general se encargaría del examen de los maestros, pero en tanto se aprobaba, lo haría la Diputación y «aprobados se les dará un título donde conste que tienen la competente instrucción, firmado por el jefe político,

${ }^{69}$ Dictamen y proyecto de decreto sobre el arreglo de la enseñanza pública, presentados a las Cortes por su comisión de Instrucción pública..., p. 17. En el Trienio, Garelly y Rey, diputados por Valencia y Cataluña, respectivamente, criticaron la centralización de las oposiciones. «Comprendo — decía Garelly- muy bien la utilidad de sujetar a todos sus profesores, para llegar a serlo, a un examen uniforme ante el cuerpo que la dirección nombrase; pero debiendo identificarse todas con un mismo método en lo sucesivo, ¿qué razón hay para que de Galicia, de Cataluña o de cualquiera otra provincia se hayan de venir a la corte todos los que traten de hacer oposiciones? ¿No fijará las reglas desde aquí la Dirección? ¿Y no podrá recibir del cuerpo examinador de cada Universidad la relación de los ejercicios y su desempeño, y el juicio de los censores, como si se hubiese hecho aquí el examen? Y pues es claro que no hay necesidad de esta extorsión, ni de los consiguientes gastos y viajes, añado ahora que hay en ello graves inconvenientes. Señor, apelo al testimonio de cuantos tienen conocimiento práctico de la enseñanza. Para enseñar con fruto no basta saber; es necesario además saber enseñar con fruto y tener afición a enseñar; y estas esencialísimas calidades solo se conocen a fuerza de reiteradas pruebas y ensayos en ejercicios literarios, presidencias, regencias y sustituciones de cátedras. Y, ¿cómo podrá apreciarlas el cuerpo examinador de la corte? A sus ojos sólo se presenta el testimonio de la oposición, que puede ser muy equívoco. Tal hombre de talento despejado brillará en una oposición si se empeña en ello, y sin embargo, encargado de la enseñanza, o no acertará, o abandonará darla el impulso conveniente; mientras que otro, sin deslumbrar, será mucho más idóneo para sacar todo el fruto posible de los discípulos que se le confíe. Repito que este conjunto de cosas, que es el que constituye un buen maestro, solo se conoce bien en el teatro donde cada cual ha operado por largo tiempo. Insisto, pues, en que no deben hacerse las oposiciones en la corte, como propone la comisión, sino en cada universidad.» También el diputado Rey se opuso a este artículo, añadiendo a la visión de Garely cuestiones más prácticas: «...yo estoy muy distante del espíritu de provincialismo y de corporación; pero creo que éste traería sus ventajas no dándole más ensanches que lo que permite una justa emulación; y de lo contrario, yo creo que el espíritu de corporación se fomenta más y más. De este modo, sólo serán los ricos los que vengan a hacer oposiciones, los cuales ciertamente no serán los más sobresalientes... y menester que no olvidemos la protección que tiene siempre el que tiene dinero... Y a estos mismos que tengan posibilidad y facultades para costear los gastos, ¿cuántas ventajas les llevarán los que hayan estudiado en la universidad de Madrid? El afecto de los maestros y las relaciones que habrán contraído ¿no les dará una superioridad sobre los provinciales y sobre todo sobre aquellos provinciales cuyas costumbres, cuyos modales y aún el idioma es tan diferente del de la corte? Cincuenta años hace que se fundó la colegiata de San Isidro y hasta ahora no ha habido en ella ningún canónigo catalán. Del mismo modo digo que tampoco habrá ningún catedrático catalán. ¿Por qué? Porque los catalanes no somos los más a propósito para estas cosas y los gallegos tampoco nos van muy adelante en esta materia; y sin embargo yo no creo que las ciencias estén vinculadas en ninguna provincia,» Diario de las sesiones de Cortes. Legislatura de 1821, 9 de junio, II, pp. 2151-2152. 
un miembro de la diputación y refrendado por el secretario e ésta. Se despachará gratis y servirá para ejercer esta enseñanza en cualquier pueblo de la provincia. ${ }^{70}$ Los absolutistas recelaron de estos nombramientos pues desde hacía tiempo en la prensa se trataba de desacreditar a los frailes y clérigos como maestros.

El problema de las escuelas que los sujetos encargados de la enseñanza no solo estén instruidos sino que... en España se encargaron clérigos y frailes que aspiraban a mantener su poder espiritual fomentando la superstición y ciñendo el espíritu de los hombres a una estúpida credulidad, desea extinguir la razón, porque cuanto menos alcanza mejor se presta al arbitrio y fines de quien la dirige. La cesión casi absoluta que se había hecho de la enseñanza a la potestad espiritual es la culpable de la escasez de talentos. Abortó el tribunal de la inquisición y privó de la libertad de pensar y de toda comunicación con las naciones más ilustradas. ${ }^{71}$

Los liberales querían controlar la educación para ir extendiendo la revolución. Y los absolutistas sabían que dejando el examen de los maestros a la dirección general y su elección a la diputación lograrían apoderarse de ella «entregándola exclusivamente a la filosofía del día.» ${ }^{72}$ Se trataba de «quitar del mundo los mejores maestros y sustituirles en quantas partes podía por los más libertinos y corrompidos. ¿Y en quántas universidades no había sabido la democracia introducir los maestros más hábiles para guiar la juventud a la disolución, a la impiedad y al libertinaje? ${ }^{73}$

\section{PROYECTO DE INSTRUCCIÓN PÚBLICA}

\subsection{Bases de la enseñanza pública}

La comisión presentó en este plan las bases fundamentales de la enseñanza pública. Se limitaba a «zanjar sus cimientos,» «a sentar las piedras fundamen-

70 Decreto CCLXIX de 23 de junio de 1813, Instrucción para el gobierno económico-político de las provincias, capítulo 2, artículo 12.

${ }^{71}$ Diario de Madrid, núm. 68, 9 de marzo de 1813 (En la Gazeta de 25 de marzo de 1812 el mismo escritor ponía de relieve que los culpables de los males de España no eran los franceses). Otro artículo en el mismo sentido puede verse en Semanario patriótico, núm. 97, jueves 13 de febrero de 1812 .

72 Instrucción Pastoral de los ilustrísimos señores Obispos de Lérida, Tortosa, Barcelona, Urgel, Teruel y Pamplona, Mallorca, Imprenta de Brusi, 1813, p. 224.

73 El Procurador general del rey y de la nación, núm. 110, domingo 18 de septiembre de 1814, p. 891-897.

(C) UNED. Revista de Derecho Político

N. ${ }^{\circ} 82$, septiembre-diciembre 2011, págs. 319-350 
tales» de un edificio que pretendía fuese uniforme y sencillo. Dejaba a reglamentos particulares su desarrollo posterior. ${ }^{74}$ La empresa hubiera sido difícil de no haber contado con los proyectos de algunos particulares y especialmente con el informe y bases que la comisión formada por el gobierno había presentado —el llamado informe Quintana_- Realmente hizo sólo unas ligeras variaciones de éste. ${ }^{75}$

Las bases se establecían de acuerdo con las aseguradas en la Constitución. Concretamente el artículo 368 — «el plan general de enseñanza será uniforme»- se entendía como fundamento del sistema. Frente a los diferentes métodos, libros y doctrinas anteriores, la enseñanza costeada por el estado sería uniforme, nacional y gratuita. Dejaba libre no obstante, la enseñanza privada. Se podía enseñar o aprender libremente, sin sujeción a estas bases, en escuelas particulares, con la única condición de no vulnerar la religión o la Constitución. ${ }^{76}$ Los absolutistas vieron con malos ojos esta uniformidad, que implicaba las mismas doctrinas y los mismos libros. También algún liberal la criticó, pero por motivos muy diferentes: «ya que todo es libre en España que no sea esclava la enseñanza. ${ }^{77}$

Ni la Constitución ${ }^{78}$ ni el proyecto recogían como base general la enseñanza en castellano, a pesar de las varias lenguas de la monarquía. No obstante, no podemos olvidar que en las escuelas de primeras letras la unificación lingüística se había ordenado ya por Carlos III. ${ }^{79}$ En 1768 mandó «que la enseñanza de pri-

74 Dictamen..., pp. 3 y 4.

75 La universidad de Salamanca también presentó un informe, pero ni ahora ni durante el Trienio se tendrá en cuenta, Mariano PESET y PILAR GARCÍA TROBAT, «Poderes y modelos universitarios, siglos XV-XIX,» Historia de la Universidad de Salamanca, Ediciones Universidad de Salamanca, 2004, II, 37-91, p. 78.

76 Dictamen..., pp. 4 y 5, artículos -6 del Proyecto.

77 Ramón SALAS, Lecciones de derecho público constitucional para las escuelas de España, 2 volúmenes, Madrid, Imprenta del Censor, 1821, II, p. 283.

78 En la discusión del proyecto de Constitución, el diputado Feliu manifestó que debía mandarse «la importantísima enseñanza de las ciencias en lengua castellana.» Recomendaba por Jovellanos, se reitera en el informe Quintana: «sea también una la lengua en que se enseñe y que ésta sea la lengua castellana.» Según QUINTANA, todos coinciden en la utilidad del castellano en las escuelas de primera y segunda enseñanza, pero no es tan fácil que convengan en su uso en las universidades, cuando es «un oprobio del entendimiento humano suponer que la ciencia de Dios y la de la justicia hayan de ser mejor tratadas en este ridículo lenguaje que en la alta, grave y majestuosa lengua española,» «Informe de la Junta creada por la Regencia...», p. 177.

79 Sobre la introducción del castellano en las escuelas de Navarra puede verse en José María JIMENO JURÍO, Navarra. Historia del euskera, Tafalla, Editorial Txalaparta, 1998. Para el castellano en Mallorca, Ma Angustias BEAS TERUEL, «Trasferencia léxica en las colocaciones con hacer y dar en el español de Mallorca desde una perspectiva diacrónica, «Tendencias actuales en la investigación 
meras letras, latinidad y retórica se haga en lengua castellana generalmente, donde quiera que no se practique, recomendándose también por mi Consejo a los Diocesanos, Universidades y Superiores Regulares para su exacta observancia y diligencia en extender el idioma general de la Nación para su mayor armonía y enlace recíproco.» ${ }^{80}$

En la segunda enseñanza el proyecto lo prescribe y en la tercera, salvo teología, derecho canónico y civil romano, los demás cursos se impartirán en castellano. En estos casos, no obstante, la extensión del castellano se entendían con respecto al latín. La Abeja española mordaz como siempre se burlaba de la importancia que se había concedido en la enseñanza: «como la lengua española se puede aprender por las calles, es del todo inútil un profesor de ella. El latín, que es un ornato de la educación, conviene, que no haya aldea, en donde no se enseñe y gaste en esto cinco o seis años del tiempo más precioso para la educación.» E incluso ironizaba sobre la traducción de la misma la Constitución al latín.

La jurisprudencia debe tener lugar... en latín, porque no es del caso estudiar las leyes patrias, que son las que están en español. Ahora hay el embarazo de la Constitución, que es la sola materia de nuestra jurisprudencia todavía; pero mientras un sabio Domine o Profesor de latinidad la traduce a un buen latín, arreglado en todos sus números al arte de Nebrixa, pueden los muchachos chillarla en la escuela o academia para instrucción de los que pasen. ${ }^{81}$

La importancia de producciones literarias en castellano, para generalizar los conocimientos a todas las clases del Estado, se puso de manifiesto antes del Proyecto. El 16 de octubre de 1813, García Page presentó una proposición pidiendo que se dijera a la Regencia que animase a los literatos españoles a que publicasen en castellano. Admitida la proposición y pasada a dictamen de la comisión de instrucción pública, la comisión opinó que debía aprobarse, y además estenderse para que también el gobierno impulsase las traducciones de obras clá-

diacrónica de la lengua, Publicacions i edicions de la Universitat de Barcelona, 2009, 197-206, p. 201; Sobre la castellanización de Cataluña, Francesc FERRER I GIRONÉS, La persecució politica de la llengua catalana, Barcelona, Edicions 62, 1986; Ricardo GARCÍA CÁRCEL, Felipe V y los españoles. Una visión periférica del problema de España, Madrid, Plaza Janés, 2002. Sobre la castellanización de los indios en la época de Carlos III, Bárbara CIFUENTES, Lenguas para un pasado, huellas de una nación. Los estudios sobre lenguas indígenas de México en el siglo XIX, México, Instituto Nacional de Antropología e Historia, 2002.

80 Ricardo GARCÍA CÁRCEL, Felipe V y los españoles..., pp. 199-200.

81 «Proyecto de instrucción pública con arreglo a los principios de las gentes de Forma,» Abeja española, núm. 305, martes 13 de julio de 1813. El Dictamen y proyecto de 1814 determinaban su estudio en castellano "¿Cabría cosa más extraña que.. para el conocimiento de nuestra Constitución prefiriésemos el indigesto latín del aula a la magestuosa y grave lengua castellana,» p. 11 
sicas «especialmente las que enseñan los sanos principios de política en que estriban las nuevas instituciones y las obras elementales a propósito para la enseñanza de la juventud.» ${ }^{82}$

El plan de instrucción pública estaba destinado a los hombres porque para las mujeres la educación debía ser doméstica y privada; «así lo exigía el destino que tiene este sexo en la sociedad, que sean buenas madres de familia.» Tampoco se entendió la importancia de la instrucción femenina en los principios liberales sino en cuanto que como madres y esposas pudieran influir en su familia. ${ }^{83}$ Solo dos artículos se dedica a su educación. Se establecerán escuelas públicas donde se enseñase a las niñas a leer y escribir y a las adultas «las labores propias de su sexo.» Las diputaciones provinciales, por encargo del gobierno, propondrán el número necesario de estas escuelas, así como dotación y plan de estudios.

El sistema educativo público, con un plan uniforme y general, se estructuraba en tres niveles: enseñanza primaria, general e indispensable que debía darse a la infancia; segunda enseñanza, que comprendía conocimientos generales para todas las ocupaciones de la vida social; y la tercera enseñanza. ${ }^{84}$

\subsection{Primera enseñanza}

En las escuelas de primeras letras aprenderían los niños a leer con sentido y a escribir con claridad y buena ortografía así como las reglas elementales de la aritmética. También estudiarían sus derechos y obligaciones civiles y religiosas mediante catecismos. ${ }^{85}$ Estos libritos, claros, breves y sencillos eran familiares al pueblo y a partir de preguntas y respuestas se inculcarían de memoria, aunque no

82 Diario de sesiones, núm. 17, 16 de octubre de 1813, p. 123; núm. 18, El 17 de octubre se admite a discusión y se pasa a la comisión de instrucción pública, p. 125. La comisión de instrucción pública presentó su dictamen, núm. 40, 6 de noviembre de 1813, p. 205. Se añadió la propuesta del diputado Maíquez, «promuévase además por el gobierno la reimpresión de las obras de autores nacionales del siglo XVI con especialidad,» Diario de sesiones, núm. 42, 7 de noviembre de 1813 , p. 210.

83 JOVELLANOS ya subrayaba esta influencia, «no perdiendo de vista que la primera educación del hombre es obra de las madres y que la instrucción de éstas tendrá el influjo más señalado en las mejoras de la educación general y en los progresos de la instrucción pública, « Bases para la formación de un plan de Instrucción pública,» Obras publicadas e inéditas, colección hecha e ilustrada por Cándido Nocedales, Madrid, BAE, 1858, I, 268-276, p. 270. Sobre su importancia como difusora de la Constitución, véase, Pilar GARCÍA TROBAT, «Enseñanza y propaganda de las ideas liberales en la mujer,» Ciencia y academia, 2 vols., Universitat de València, 2008, I, 371-384.

${ }^{84}$ Dictamen..., pp. 5-6.
${ }_{85}$ Proyecto..., artículo 10. 
se entendieran por entero, la religión y la Constitución. ${ }^{86}$ No se llegó a prescribir qué catecismo debía utilizarse. Se dejó libertad. Pero sí se incidió en la importancia de «grabar en el corazón de los niños los principales dogmas de nuestra divina religión, las máximas más sencillas de moral y buena crianza y una idea acomodada a su alcance de los principales deberes y derechos del ciudadano,» porque a esa edad se fijaban impresiones que no se borraban en el resto de la vida. ${ }^{87} \mathrm{Mu}-$ chos particulares comenzaron a publicar obras elementales. En la prensa se informa de los que van apareciendo e incluso se determinan los más adecuados. Se alaba el Catecismo patriótico o breve exposición de las obligaciones naturales, civiles y religiosas del buen español compuesto por un párroco del arzobispado de Toledo.

Este catecismo que se anuncia al público es enteramente distinto del otro publicado ya con el título de Catecismo político, que es una explicación de la Constitución poco adecuada para los niños de las escuelas de primeras letras. Este que se publica de nuevo es justamente la breve exposición de las obligaciones civiles de que se habla la misma Constitución en el título IX, capítulo Único, artículo 366; consta de solos doce capítulos mui cortos y se ha procurado formar por el estilo y método del Catecismo de Ripalda. ${ }^{88}$

La prensa absolutista es más suspicaz: los catecismos trataban no de ilustrar sino dirigir la opinión pública, empezando desde los más jóvenes. ${ }^{89}$

Según el proyecto, las notas características de esta enseñanza debían ser la universalidad y la gratuidad.

86 Véase, Mariano PESET y Pilar GARCÍA TROBAT, «La Constitución de 1812 o cómo educar...», pp. 27-31. Los catecismos que más se difundieron entre las escuelas de primeras letras, durante la primera experiencia liberal, fueron: El Catecismo político arreglado a la Monarquía española para la ilustración del pueblo, instrucción de la juventud, y uso de las escuelas de primeras letras, por D.J.C. Córdoba, imprenta Real de D. Rafael García Domínguez, año de 1812. El Catecismo patriótico o breve exposición de las obligaciones naturales, civiles y religiosas de un buen español, compuesto por un párroco del arzobispado de Toledo, Madrid, imprenta de Ibarra, 1813. Las Lecciones políticas para el uso de la juventud española del Dr. D. Manuel CEPERO, cura del Sagrario de Sevilla, impreso por D. Josef Hidalgo, año 1813; El Catecismo político español constitucional que a imitación del de Doctrina cristiana que compuesto por el Señor REINOSO presenta al público E.D.D.E.A., Málaga, oficina de D. Luis Carreras, 1814; Y el Catecismo cristiano político compuesto por un Magistrado para la educación de su bijo y dado a luz por el Ayuntamiento de Antequera para el uso de sus escuelas, Antequera, impreso por la viuda e hijos de Gálvez, 1814. En febrero de 1816 se prohibió la circulación de estos catecismos, calificados de contener doctrina «subversiva, sediciosa y destructora del orden público,» se mandó recoger todos los ejemplares, exigiendo que los impresores dieran razón individual de los autores de las ediciones anónimas acordó, Recogido en Gaceta de Caracas, núm. 71, miércoles 17 de abril de 1816, pp. 549-550.

${ }^{87}$ Dictamen..., p. 6.

88 Diario de Madrid, núm. 181, miércoles 30 de junio de 1813, p. 725.

${ }^{89}$ La Píldora, número 42, jueves 27 de mayo de 1813, p. 166. 
Universalidad. La universalidad era necesaria para que la nación tuviese aquella cultura general indispensable para mejorar las costumbres. Sin educación eran inútiles las mejores leyes. Su importancia se advertía en la Constitución al prescribir en el artículo 366 de la Constitución: «en todos los pueblos de la Monarquía se establecerán escuelas de primeras letras, en las que se enseñará a los niños a leer, escribir y contar, y el catecismo de la religión católica, que comprenderá también una breve exposición de las obligaciones civiles.» El artículo 12 del proyecto para facilitar su observancia disponía que:

1.- en cada pueblo que llegase a cien vecinos no podía dejar de haber una escuela de primeras letras;

2.- las poblaciones de menor vecindario, donde no hubiese escuela, las diputaciones provinciales propondrían el modo de que no carecieran de esta primera enseñanza;

3.- en los pueblos de gran vecindario se establecería una escuela por cada quinientos vecinos.

Gratuidad. La educación no se regulaba como un derecho de los españoles sino como una obligación del estado porque después de prescribir en el artículo 25 que «desde el año 1830 deberán saber leer y escribir los que de nuevo entren en el ejercicio de los derechos de ciudadano ${ }^{90}$ sería injusto que no facilitara la instrucción a todos los individuos y además hacerlo gratuitamente. ${ }^{91} \mathrm{El}$ artículo 25 no se entendió de la misma forma por todos. Mientras unos consideraban que aunque no se conocía «legislación alguna que exija la condición de saber leer y escribir para ejercer todos los derechos civiles, pero sin embargo veo y aplaudo en nuestro legisladores la intención de extender la instrucción en que se ha estado hasta ahora muy atrasada España... ${ }^{92}$ Otros, veían que era un modo de entregar el gobierno de España a «una porción de varones, que por su desgracia no hubieran podido aprender ni a escribir ni a leer,» pues hasta 1830 no se exigía ni a electores ni a elegidos. ${ }^{93} \mathrm{Y}$ entendieron que el establecimiento de escuelas gra-

90 Es una disposición constitucional porque las Cortes han querido que los españoles que no vegeten como los brutos, sino que raciocinen haciendo uso de sus facultades intelectuales, Diario de sesiones, 968, 9 de septiembre de 1813, p. 6174.

${ }^{91}$ Dictamen, p. 6.

92 Ramón SALAS, Lecciones de derecho público..., II, p. 53.

93 Remedio fumigatorio, igneo, fulminante, extremo (extremo de ordenada caridad) que el obispo de Santander movido por Reales Órdenes, copiadas en el Escrito, procuraba a los que pueden hallarse por su Obispado; y en confianza de la eléctrica, Christiana Fraternidad, difundida por todos los otros Obispados del Reyno) a los que hay en España enfermos pestiferos, moribundos, víctimas de la infernal Philosophia, Volteri-Napoleonina, Santander, Oficina de Josef Manuel de Mendoza, 1816, p. 126. 
tuitas tenía el fin de establecer las «sanas doctrinas» de los liberales entre los infelices. ${ }^{94}$

El Proyecto prefijaba el mínimo de la dotación anual del maestro; exigía que fueran examinados; y sujetaba su elección, vigilancia de su conducta y remoción a las autoridades locales. Las diputaciones provinciales serían responsables de establecer estas escuelas y debían dar cuenta al gobierno de haberlo verificado. ${ }^{95}$

\subsection{Segunda enseñanza}

La segunda enseñanza no se calificaba como universal, sino como general y fácil de adquirir. Su falta se reputaba causa del atraso en que se hallaba la educación. Al salir de las escuelas los que querían dedicarse a las artes, al comercio u otras profesiones - la mayor parte de los destinos de la sociedad — se veían privados de esta enseñanza intermedia por no haber establecimientos públicos. Sólo los que iban a continuar sus estudios en alguna facultad, encontraban clases costeadas por el estado, pero aún ellos se resentían de la falta de una enseñanza preparatoria suficiente. ${ }^{96}$

Para evitar estos inconvenientes se establecían las Universidades de provincia tanto en la Península y como en Ultramar. ${ }^{97}$ En cada una de ellas habría una biblioteca pública, ${ }^{98}$ un gabinete de historia natural, otro de instrumentos de física y modelos de máquinas, salas de dibujo y un jardín para botánica y agricultura. La enseñanza sería en castellano y el gobierno quedaba encargado de promover obras elementales para la enseñanza de la juventud. ${ }^{99} \mathrm{La}$ segunda en-

94 La Píldora 16, núm. 42, jueves 27 de mayo de 1813, p. 165

95 Proyecto, artículos 13-19.

96 Dictamen, pp. 7-8.

97 Art. 22 «En la Península e islas adyacentes habrá una de estas universidades en la capital de cada provincia, según se halle dividido el territorio. Y por lo respectivo a Ultramar, las habrá en la provincia de Nueva España, en México, San Luis Potosí, Puebla, Valladolid, Oaxaca, Orizaba y Querétaro; en la de Nueva Galicia, en Guadalaxara y Zacatecas; en la de Yucatán, en Mérida y Villahermosa; en las internas de Oriente, en el Saltillo; en las de Occidente, en Chihuahua y Arispe; en la de Goatemala, en Goatemala, León de Nicaragua y Chiapa; en la de Filipinas, en Manila; en la de Cuba e Islas, en la Habana, Cuba, santo Domingo y Puerto Rico; en la del Perú, en Lima, Cuzco, Arequipa y Truxillo; en la de Buenos Aires, en Charcas, Buenos Aires, Potosí y Oruro; en la de Venezuela, en Caracas, Maracaybo y Guayana; en la de Chile, en Santiago y Chillan; y en la del Nuevo Reino de Granada, en Santafé, Quito, Guayaquil y Panamá.»

98 El jefe político de Madrid dispuso que continuase, según estaba mandado, entregando a la biblioteca de los estudios de San Isidro, un ejemplar de todo género de impresos que se publicasen en la capital, en beneficio de la juventud. Diario de Madrid, núm. 263, lunes 20 de septiembre de 1813.

99 Proyecto, artículos 28 y 29. 
señanza comprendía la enseñanza de ciencias matemáticas y físicas, ciencias políticas y morales y de literatura y artes.

La enseñanza de las ciencias físicas y matemáticas se distribuirá en la forma siguiente:

Matemáticas puras

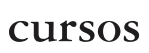

Física general

Mecánica elemental aplicada a las artes y oficios $\quad 1$

Historia natural

Botánica aplicada a la agricultura 1

Química y mineralogía aplicada a las artes y oficios 1

La enseñanza de la literatura y artes comprendía los cursos siguientes:

Gramática española

cursos

Geografía y cronología

1

Lengua latina

Lógica

Literatura, historia

Dibujo natural y geometría descriptiva

La enseñanza de las ciencias morales y políticas comprendían:

Moral y derecho natural

cursos

Derecho político y Constitución

Economía política y estadística

El estudio de la Constitución, prescrito por la Constitución en el artículo 368, lo establecía la comisión en esta etapa de la enseñanza más general que la superior. Era necesario «que aprendiendo los principios del derecho político, sepan las reglas de cuya observancia depende el justo régimen y la felicidad de las naciones; y que instruidos en los principios generales de esta ciencia, los apliquen después a su patria, y estudien las leyes fundamentales que la rigen, para ver su consonancia con los principios constitutivos de la sociedad y amar por convencimiento propio lo que deben respetar por obligación» ${ }^{100}$

100 Dictamen..., p. 10. 
El Dictamen y proyecto no concretan más: ni duración de cursos, ni orden en los estudios, ni vacaciones, ni horas... pues «quanto pertenezca a la organización de estas universidades como cuerpos y a sus relaciones económicas y gubernativas, lo determinarán los reglamentos particulares.» ${ }^{101}$

\subsection{Tercera enseñanza}

Los estudios de carrera o facultad, como eran necesarios solo para algunas profesiones de la vida civil (artículo 36), se consideraban particulares y reducidos a varios establecimientos. Estos estudios se proporcionaban unos, en universidades mayores y otros, en colegios o escuelas particulares. Las 11 universidades del anterior plan se reducían a 9 en la península y 1 en Canarias; ${ }^{102}$ para Ultramar, 14. La universidad de provincia se unirá a la mayor, donde la hubiere, «como un solo cuerpo,» bajo el mismo régimen económico y gubernativo. ${ }^{103}$

En todas las universidades se enseñará teología y jurisprudencia civil y canónica, con los estudios auxiliares útiles para estas ciencias.

Estos estudios auxiliares se distribuirán en la forma siguiente

$\begin{array}{lc}\text { Lengua hebrea } & \text { cursos } \\ \text { Lengua griega } & 1 \\ \text { Historia literaria y bibliografía } & 1 \\ \text { Numismática y antigüedades } & 1 \\ & 1\end{array}$

La enseñanza de la teología se distribuirá en la forma siguiente

Fundamentos de la religión, historia de la teología y

lugares teológicos 1

Instituciones dogmáticas y morales 3

Sagrada Escritura 1

Liturgia, práctica pastoral y ejercicios de predicación $\quad 2$

101 Dictamen, p. 11.

102 Proyecto, artículo 39 Las de la Península se establecerán en Salamanca, Santiago, Burgos, Zaragoza, Barcelona, Valencia, Granada, Sevilla y Madrid; y las Universidades mayores de Ultramar, en México, san Luis Potosí, Guadalaxara, Mérida de Yucatçán, Saltillo, Chihuahua, Goatemala, Manila, Habana, Lima, Charcas, Caracas, Santiago y Santafé.

103 Proyecto, artículos 52 y 53. 
Especial cuidado se pone en la carrera de jurisprudencia. Su estudio se consideraba una pérdida de tiempo. Así lo explicaba un estudiante de la universidad de Caracas. En los cuatro años de derecho civil estudiaban las Instituciones de Justiniano, explicadas por el brevísimo compendio de Antonio Pérez ordenado en preguntas y respuestas y por el comentario de Vinnio con las adiciones del pavorde Sala. Las leyes patrias eran consideradas en aquella cátedra un apéndice de las romanas, «cuyos cuerpos se veneran con superstición y se tienen como un tesoro inagotable de oráculos pronunciados para regir eternamente en las naciones civilizadas;» no se hablaba, sino de pasada, de las disposiciones del derecho español, y en cualquier caso se interpretaban por las constituciones romanas y por las respuestas y opiniones de los antiguos jurisconsultos incluidos en la «indigesta recopilación de Triboniano.»

$\mathrm{Ni}$ el catedrático tiene obligación de enseñar otra cosa por las constituciones académicas, ni los alumnos de estudiarla; de manera que al concluir estos su curso se encuentran ignorantísimos en las leyes de su patria, mientras que se les han hecho aprender las más minuciosas fórmulas que estuvieron en práctica en la república romana, y que desaparecieron con ella después de tantos siglos. Nada de historia, de derecho natural y de gentes y mucho menos del político de las naciones; todo estos se ha tenido por inútil y perjudicial y ni la cátedra de Constitución ha llegado a erigirse en la universidad de Caracas. ${ }^{104}$

El Proyecto de 1814 distribuía laa enseñanza de la jurisprudencia ${ }^{105}$ en la forma siguiente:

104 El Espectador, núm. 513, lunes 9 de septiembre de 1822, pp. 605-606.

105 «No puede haber cosa más extraña, ni prueba más evidente de las extravagancias en que puede dar el capricho de los hombres, no solamente en España sino en otras muchas provincias de la Europa, que teniendo leyes propias y acomodadas al genio a las costumbres y demás circunstancias de su pays, todo el estudio de sus sabios se ha ocupado por mucho tiempo en aprender interpretar y combinar las del derecho romano, que o por el transcurso de los tiempos o por otras muchas causas, son obscuras, muchas veces contrarias entre sí y ciertamente inferiores en autoridad a las del Derecho patrio. A pesar de los cambios introducidos por Felipe V, todavía no se había innovado nada en el método de estudiar la jurisprudencia. En 1713 se había tratado de que se estudiara derecho real en las universidades, se mandó en 1741 como consta en auto 3 libro 2, título I de los acordados, pero sin efecto.» Reflexiones sobre el buen gusto en las ciencias y en las artes. Traducción libre de las que escribió en italiano Luis Antonio Muratori, con un discurso sobre el gusto actual de los españoles en la literatura, por Juan SEMPERE y GUARINOS, Madrid, Imprenta de don Antonio de Sancha, 1782, pp. 268-269. Sobre la difícil y tardía introducción del derecho patrio en nuestras universidades, véase, Mariano PESET, «Derecho romano y Derecho real en las Universidades del siglo XVIII,» Anuario de Historia del derecho español, 1975, 273-339. 


\section{cursos}

Principios de legislación universal e historia

del derecho civil

Elementos de derecho civil romano

Instituciones de derecho español

Fórmulas y práctica forense

La enseñanza del derecho canónico será común a teólogos y juristas y se distribuirá en los siguientes cursos:

Historia y elementos de derecho público eclesiástico

cursos

Instituciones canónicas

Historia eclesiástica y suma de Concilios

Para poderse matricular en estas facultades era necesario certificar haber ganado dos cursos en legua latina y uno en matemáticas, física general, gramática castellana, geografía y cronología, lógica, literatura e historia, moral y derecho natural y derecho político y Constitución. Además uno en economía política y estadística para los que se quisieran dedicarse a la jurisprudencia. ${ }^{106}$

El Plan además proponía el establecimiento de una Universidad central en Madrid como si fuera una «escuela matriz»; como modelo de las demás, debía reunir a los sabios más distinguidos y a los discípulos más aventajados. En ella se formarían obras elementales, los métodos más fáciles y sencillos para la uniformidad de enseñanza. En Ultramar, las universidades de Lima y México, jugarían la misma función. ${ }^{107}$

En escuelas particulares se enseñaría la medicina unida a la cirugía, ${ }^{108}$ veterinaria, ${ }^{109}$ agricultura experimental, ${ }^{110}$ Bellas Artes, ${ }^{111}$ música, ${ }^{112}$ escuelas de

106 Proyecto, artículos 49 y 50.

107 Dictamen, pp. 14-15.

108 En Madrid, Cádiz, Barcelona, Burgos, Santiago, Lima, México y Guatemala.

109 En Madrid, México y Lima.

110 En Sanlúcar de Barrameda y Valladolid y en Terma (Perú), Aguascalientes (Nueva España) y en Guatemala.

111 En las academias de Madrid, Valencia, Zaragoza, Valladolid y Sevilla y en México, Guadalaxara, Guatemala y Lima.

112 En las escuelas de Madrid, México y Lima. 
comercio, ${ }^{113}$ construcción de canales, puentes y $\operatorname{caminos}^{114}$ y astronomía y navegación. ${ }^{115}$

\section{De los Fondos}

El artículo 335. 5 de la constitución encargaba a las diputaciones provinciales el promover la educación de la juventud y el artículo 321.5 dejaba a cargo de los ayuntamientos el cuidar que las escuelas se pagasen de los fondos del común. La Instrucción para el gobierno económico-político de las provincias regulaba estas competencias. ${ }^{116}$ Pero el problema fundamental con que se encontraron fue la falta de dotación. No porque no se hubiera invertido en ella sino por su mala administración.

Si se sumara todo lo que cuestan al Estado, las universidades, los colegios, las pensiones, las academias, las bibliotecas, los laboratorios, los ensayos y viajes pagados por el erario, y todo lo que ha gastado el Estado en la enseñanza de sus súbditos, se vería que no hay nación alguna que haya invertido mayores cantidades en la enseñanza pública. ${ }^{117}$

Por eso pretendieron antes que nada, recabar información sobre el estado de los establecimientos de instrucción. El Dictamen dejaba en manos del gobierno la averiguación de los fondos que cada provincia destinaba a la enseñanza pública y la propuesta del método más oportuno para administrarlos y evitar se destinasen a otros fines. Caso de resultar un deficit para costear lo previsto en el plan, el gobierno debía proponer a las Cortes el modo de cubrirlo. ${ }^{118}$ El Periódico ministerial explicaba a los jefes políticos cómo recabar esta información.

...decir que hay tantas escuelas de primeras letras en la provincia, tantas de gramática, tantas universidades, tantas cátedras, es no decir nada, si no se toma un conocimiento del estado que tienen las escuelas, de sus métodos de sus adelantamientos, o del perjuicio y retraso que sufren las ciencias, ya por defecto de los maestros, ya por su indotación, ya por la falta de sistema y ya por los vicios que reinen procedentes de las opiniones de los siglos anteriores sobre ciertas materias.

113 En Madrid, Cádiz, Barcelona, La Coruña, Bilbao, Málaga, Lima, Guayaquil, Valparaíso, La Habana y Manila.

114 En Madrid, Lima y México.

115 En Cartagena, Cádiz, El Ferrol, Lima, La Habana y Manila.

116 Decreto CCLXIX de 23 de junio de 1813.

117 Dictamen, p. 20

118 Dictamen, 119-121. 
Los jefes políticos... son los que deben dar los materiales al Gobierno para las reformas. Muy bueno y conveniente será que se oyga a los ayuntamientos a quienes peculiarmente está encargada la instrucción pública. ${ }^{119}$

Pero se encontraron con el problema de la desconfianza. Algunos ayuntamientos persuadidos de que se pretendía echar mano de estos fondos para cargarles más contribuciones, ocultaron la verdad. El gobierno se vio obligado a requerir de las corporaciones científicas y de cualquier ciudadano información acerca de las asignaciones a la enseñanza que o por omisión de los patronos, o por ignorancia de los interesados o por malicia de los administradores o por el trastorno producido a consecuencia de la guerra o por cualquier otras causas no se estuvieran aplicando a su verdadero destino. ${ }^{120}$

Pero el proyecto llegó tarde. Con la vuelta de Fernando VII se volvió a tratar la cuestión de los planes de estudios. El tejer y destejer del que hablará Unamuno. Las Universidades no querían la uniformidad, sino volver a sus antiguos estatutos... En 1820, las Cortes volverán a retomar las inquietudes gaditanas.

Title:

INSTRUCTED BY THE SPANISH CONSTITUTION

\section{Summary:}

1. Introduction. 2. Constitution and freedom of press: 2.1. Freedom of the press and Inquisition. 2.2. Teaching the Constitution. 3. Department of education. 4. Draft plan of public instruction: 4.1. Bases of public education. 4.2. Primary education. 4.3. The second lesson 4.4. Third lesson 4.5. Of the funds.

\section{Resumen:}

La instrucción pública fue una de las preocupaciones principales de las Cortes gaditanas desde su formación hasta el regreso de Fernando VII. Las Cortes parecen unir Constitución e instrucción como palancas de modernización del país, y buen indicio de ello es el mandato que hace el texto fundamental de enseñanza de la propia Constitución. Pero, junto a ello, y como claro complemento dedicaron también atención preferente

119 Periódico ministerial, núm. 1, 1814, pp. 18-20.

${ }^{120}$ Circular del gobierno superior político de la provincia de Valencia, El conde de Almodóvar, Valencia 28 de julio de 1820, Diario de Valencia, 1 de agosto, pp. 286-287. 
a la libertad de imprenta, con cuya ocasión hubieron de lidiar con el problema de las relaciones con la Iglesia Católica, especialmente por la existencia de la Inquisición. Concluye el trabajo con dos análisis: uno, de la Dirección General de Estudios, creada por disposición del artículo 369 de la Constitución, con dos subdirecciones para las provincias de Ultramar; y el segundo, sobre el Proyecto de Plan de Instrucción Pública, que había de ser uniforme en toda España, pero que no llegó a fraguar por el regreso del absolutismo.

\begin{abstract}
:
Public education was one of the main concerns of the Cortes of Cadiz from its formation to the return of Fernando VII. The courts seem to unite Constitution and instruction as levers to modernize the country, and a good indication of this is the command that does the basic text for teaching the Constitution. But alongside this, as clear complement also devoted special attention to freedom of the press, on which occasion had to deal with the problem of relations with the Catholic Church, especially by the existence of the Inquisition. Work concludes with two reviews: one from the Directorate General for Research, created by operation of Article 369 of the Constitution, with two branches to the overseas provinces, and the second on the Draft Plan of Public Instruction, which had to be uniform throughout Spain, but failed to forge the return of absolutism.
\end{abstract}

Palabras clave:

Constitución, instrucción pública, libertad de imprenta, Inquisición, censura.

Key words:

Constitution, public education, freedom of the press, the Inquisition, censorship. 